HORIZON 8 (2) 2019 : II. Translations and Commentaries : N. Hartmann :

Trans. by E. Ananieva : 641-669

ФЕНОМЕНОЛОГИЧЕСКИЕ ИССЛЕДОВАНИЯ • STUDIES IN PHENOMENOLOGY • STUDIEN ZUR PHÄNOMENOLOGIE • ÉTUDES PHÉNOMÉNOLOGIQUES

https://doi.org/I0.21638/2226-5260-2019-8-2-64I-669

НИКОЛАЙ ГАРТМАН

ГЕГЕЛЬ И ПРОБЛЕМА РЕАЛЬНОЙ ДИАЛЕКТИКИ ${ }^{1}$

ЕКАТЕРИНА АНАНЬЕВА (пер. с нем.)

Кандидат философских наук, старший преподаватель.

Санкт-Петербургский государственный университет, Институт философии.

199034 Санкт-Петербург, Россия.

E-mail: e.ananeva@spbu.ru

NICOLAI HARTMANN

\title{
HEGEL AND THE PROBLEM OF REAL DIALECTICS
}

\section{EKATERINA ANANIEVA (trans. from German)}

$\mathrm{PhD}$ in Philosophy, Senior Lecturer.

St Petersburg State University, Institute of Philosophy.

199034 St Petersburg, Russia.

E-mail: e.ananeva@spbu.ru

\section{I}

Прошло сто лет с момента рождения гегелевской философии. Она давно стала частью истории и безвозвратно ушла в прошлое. Она царствовала, была свергнута, заслонена новой метафизикой; была забыта и объявлена мертвой,

1 Перевод выполнен по изданию: Hartmann N. Kleinere Schriften, Bd. I: Abhandlungen zur systematischen Philosophie, Berlin: Walter de Gruyter \& Co, 1955, S. 323-346.

Печатается с любезного разрешения издательства Walter de Gruyter GmbH.

○ DE GRUYTER

(C) EKATERINA ANANIEVA, trans., 2019 
но в последние десятилетия неожиданно обрела новую жизнь и, вероятно, сыграет очень важную роль в общем обновлении метафизического мышления, о котором мы свидетельствуем. Поэтому сегодня мы имеет нечто большее, чем просто исторические причины, чтобы задуматься над тем, чем была эта философия в самом своем существе, что в ней погибло, что осталось в живых. Это своего рода отчет, перепроверка, которые сегодня привлекают многие лучшие умы. Внутренняя необходимость полемики заставляет нас делать это. Великое - это то, что всегда притягивает величие.

На пороге любого ее понимания стоит проблема гегелевской диалектики. Представляет ли она собой просто внешнее одеяние или содержание философии Гегеля, - это уже другой вопрос. По крайней мере, вы не можете без овладения этой проблемой ни войти в нее, ни из нее выйти. Если вы оставите ее в стороне, мир мысли Гегеля останется закрытым для вас. Любая попытка переведения этого мира мысли в недиалектическую форму проигрывает оригиналу. Она будет и останется суррогатом. Она не ведет вглубь гегелевской философии, не говоря уже о том, чтобы превзойти ее, поскольку она ведет мимо нее. Также мало понимают истинное положение дел те, кто снова сегодня изучает Гегеля и обнаруживают проблемы, которые волнуют наше время.

Этому противостоит подход, который стал популярным в XIX веке, а именно, что диалектика - всего лишь трюкачество, ловкость обращения будь то с мыслями, будь то с понятиями. Согласно этой точке зрения, объекты знания остаются совершенно незатронутыми в диалектическом мышлении; мышление проходит мимо них, теряет связь с ними, создает им на смену суррогаты и теперь движется в них, свободно конструируя, не встречая никакого сопротивления. Именно этот подход в своей великой реакции на него завершил Гегель своей философией, преодолел его и окончательно оставил его позади. Сегодня по-прежнему распространено такое мнение, которого придерживаются многие, возможно даже большинство как внутри философской профессии, так и вне ее. Оно встречается там, где отсутствует непосредственное знакомство, занятие философией Гегеля, и остается только историческое сознание ее прежнего величия и ее последующего падения.

Все это еще ощутимо близко. По высоте обобщений гегелевской диалектики, смелости ее выводов мало что может сравниться с ней. Она породила буйный рост спекулятивного конструирования, которое заслуживает свержения, которым она болеет. В натурфилософию сегодня сложно вписать 
научные подходы Гегеля. И нельзя отрицать также, что соблазн, который в свое время порождала философия Гегеля в этой сфере, тесно связан с неограниченным использованием его диалектической схемы. Как минимум это в значительной степени благоприятствовало отчуждению от опыта, скрывая внутренние источники ошибок спекуляций и тем самым симулируя доказательную силу, которая не имела ничего общего с отношением к вещам.

Всего этого нельзя скрыть. Здесь кроется слабость метафизики Гегеля. Но эта слабость и не одинаково распределена в различных сферах, и корень ее не в диалектической форме мысли. Гегель с самого начала был философом духа; его мышление было с самого начала теологическим, историческим, социологическим (последнее понимаемое в широком смысле). Тот факт, что он видел в природе вновь обретаемую власть духа, что он рассматривал природу как иерархию его «инобытия», столь же мало его собственная мысль, как и характеристическая черта его философии. Это скорее общий род мировоззрения пост-кантианского идеализма и романтизма, он отступает у Гегеля на задний план, если мы представим рядом с ним Баадера, Новалиса, Шеллинга.

Диалектика явно уходит корнями в философию духа. Здесь она вырастает из отношения к объекту, пожалуй, даже из его собственной объективной структуры. Нужно присмотреться к этой области, если вы хотите обнаружить ее. Здесь она может предъявить свои достижения, которые не имеют ничего общего с метафизическими предпосылками рационального идеализма. Если судить лишь по результатам, определяемым в понятиях, то невозможно обнаружить эти достижения. Вот почему дилетантское мышление расправляется с Гегелем так быстро. Совсем другое дело, если вы научитесь ценить развертывание проблем самих по себе, решения всех видов, принимаемые с предусмотрительностью. Для философски образованных и самостоятельно мыслящих умов это нечто само собой разумеющееся; только обращение к началам дает познанию результаты. Для понимания Гегеля здесь кроется conditio sine qua non. Потому что гегелевская диалектика - это разворачивание и обсуждение проблем высшего порядка. Он вынес на свет сознания совершенно новый, ранее неслыханный комплекс проблем, тем самым делая их познаваемыми и отслеживаемыми.

В этом пункте Гегель сравним с Аристотелем. Как этот последний распространил свои «апории» на все области, независимо от их разрешимости, так и Гегель - свои все новые тезисы и антитезы. То, как он пытается опосредовать их синтезом, может подвергаться критике в отдельных 
случаях; но открытие самого противоречия - теперь его можно трактовать как противоречие или как внутреннее напряжение, или как-то еще, это шаг за шагом чистое обнаружение проблем. Обычно уделяют слишком мало внимания конструктивной метафизике его синтезов, позволяя себя ослепить построением системы, и даже считалось, что это лучший способ оправдать Гегеля. По правде говоря, этим не достигается совершенно ничего в проникновении вглубь его мыслительной работы. Только когда спор о его системе завершается, начинается собственно оценка дела его жизни, оценка его философского наследия. Ибо, как и у всех великих мыслителей, так и в случае с Гегелем, исторически обусловленное и преходящее следует отличать от вневременных достижений и от того, что в однажды разработанном навсегда останется пребывающим. Нужно только найти подход для различения одного от другого.

Гегель оставил нам в наследство открытый им проблемный материал, который вряд ли можно считать богатством - он не имеет ничего общего с богатством. Он не содержится в спекулятивных озарениях, его не стоит искать и там, где развиваются основы системы; ни философия религии, ни родственная ей «логика» не могут рассматриваться в качестве ориентиров. Такими ориентирами могут быть сделаны только области конкретной духовной жизни, когда они становятся объектами проникновения в его мышлении, поскольку это самое проникновение имеет форму диалектики, и здесь форма оказывается неразрывна с содержанием - задействованным ею проблемным материалом. Это области этоса, права, государства, искусства, истории, и прежде всего там, где они переплетаются в подвижное единство. Его первый великий шедевр, «Феноменология духа», оставался основной работой в этом отношении, поскольку его философия, понятая в ее самом ценном активе, является одной большой феноменологией интеллектуального сражения, создания, постижения и формирования. Это дух как в малом, так и дух в большом (дух исторического), который формирует здесь объект. Это не случайно, и в этом не двусмысленность «феноменологии», что психологически-персональные и макро-космически-социальные явления тесно переплетены здесь друг с другом. Это, напротив, точнейшим образом соответствует двойному способу возникновения единой духовной жизни в нас, которую мы всегда отсчитываем от нашего исторического начала времен (детства), и в то же время ней неизменно присутствует нечто вневременное, собственное, неотъемлемое, с собственной свободой и собственной инициативой. 
С другой стороны, можно спросить: какое все это имеет отношение к диалектическому методу? Что достигается тезисом, антитезой и синтезом? Это в основном только логический схематизм мышления, который более похож на попытку соединить в одном движении самое разнородное, как попытку позволить родственному проявиться в его своеобразии. Такое ощущение оправдано, и от него к середине XIX века диалектика, как она практиковалась гегельянцами, основательно устала. Из этого ощущения исходил в то время философский вкус и искал, отворачиваясь от диалектического мышления, непосредственного контакта с опытом.

Это уклонение было оправдано. Всякий род философствования может начать перерождаться. Диалектическое мышление начало становиться в гегелевской школе догматическим, становиться наростом, почти болезнью. Мастерство Гегеля было чем-то уникальным, его нельзя было ни унаследовать, ни воспроизвести; воспроизведение должно было стать подражанием, подражание - схемой. Здесь кроется причина падения гегелевской школы, позитивистская реакция и постепенное забвение Гегеля. Но это именно вопрос о том, насколько в этих эксцессах диалектическое мышление само заявило свое философское право. Была ли у Гегеля диалектика универсальной схемой мышления? И составляет ли эта трех-тактность тезиса, антитеза и синтеза его сущность? Разве мы не должны, напротив, узнать из плодотворности разворачивания проблемы, что это в основном нечто совершенно иное, что оно не совпадает с этой схемой?

Последнее должно быть достаточно очевидным. Разумеется, за игрой противоположностей мог скрываться фундаментальный закон. Но, как бы то ни было, он мог быть только формальным, поскольку мог касаться только общего в диалектических путях мысли. Но гегелевская диалектика отличается тем, что она объемлет несметное многообразие - не только объектов, но и ментальных траекторий. Просто форма всюду иная. В работах Гегеля среди сотен диалектических развитий нет таких двух, которые могут быть сравнимы формально и поставлены на одну доску. Конечно, этого нельзя увидеть, если взглянуть на эту сеть идей «извне» в качестве невовлеченного, потому что так можно обнаружить только внешнее, типологию, общее. Поскольку, разумеется, и здесь есть типология. Нужно только вступить внутрь, не следует избегать пользоваться собственным мышлением, нужно ловить внутренний ритм 
мысли, и тогда картина начнет меняться. Схема исчезает, отходит на второй план; появляется сильно разветвленная структура максимального внутреннего богатства, в которой трудно уловить созвучие. Причина этого заключается в огромной гибкости и взаимной согласованности самого диалектического мышления. Диалектика поэтому совершенно отлична от других методов. Дедукция может только субсуммировать, индукция - только приводить к общему, анализ - только прояснять, эксплицировать; все они ограничены несколькими основными схемами мысли. И они всегда предполагают главное, - фактическое предъявление объекта. Иначе обстоит с диалектикой. Она представляет собой род самого усмотрения, интеллигибельное движение проникновения; она - последовательное делание видимым новых и новых сторон объекта и, таким образом, представляет собой действительно соотносительный этому усмотрению род движения объекта. Так и только так следует понимать, что она может предоставить методически понятую путеводную нить для разворачивающейся «феноменологии духа», то есть для непрерывного усмотрения проявлений духовной жизни. Это та причина, по которой нельзя ее препарировать логическим скальпелем и предварительно проанализировать; и причина, по которой вы не можете ей научиться. С ней, как и со всякой требующей мастерства продуктивной духовной деятельностью: можно, если иметь орган для этого, овладеть ею и плодотворно применять ее, но нельзя на основании этого высказать или научить, как это делается. Этому соответствует большая редкость диалектического дара - даже среди великих умов в истории философии. Гегель обладал мастерством метода, но он тоже не мог сказать, в чем оно состоит. То немногое, что мы знаем от него в высказываниях об этом мастерстве, скорее скрывает тайну, чем раскрывает ее. То, что он видел ясно, было только внешностью, схемой, трех-тактностью ступеней, подъемом к высшим образованиям. Но если бы она работала в его мышлении именно так, он бы никогда не смог справиться с ее помощью с огромным количеством проблем, которые он прояснил на все времена.

Все реальные и продуктивные методы вырастают на объектах. Это сказка, в которую верят лишь неразумные, что к любому объекту можно приступить с любым методом исследования. Это никоим образом не может быть сделано, всегда можно только нащупать точки, зоны проникновения, и то в их отдельности. Это - предлагаемые обстоятельства, и только их одних нужно держаться. Но через них проясняется путь, который следует выбрать для дальнейшего движения во внутреннее вещей. Можно пропустить этот 
путь, можно пропустить уже и подходы. Но если мы не ходим этого, наши руки не будут развязаны, чтобы действовать произвольно, но следует внимательно выспрашивать у вещей их возможности, которые они предоставляют. Метод, который признает право предмета, будет ничем иным, как следованием за ним и формированием по его образцу, податливым приспособлением к нему. И так проявляется особенность, которая на первый взгляд может показаться парадоксальной: каждый объект требует своего, единственно возможного и необходимого метода. Не существует переноса метода с объекта на объект; то есть он существует, но только в качестве варианта пропустить верный путь. Поэтому нет обобщения методологических решений, нет схематики процедуры - если эта процедура плодотворна.

Это, можно сказать, фундаментальный закон всего философского познания - многократно опровергнутый, и конечно, закон, в который никто не верит, пока самый горький личный опыт этому не научит, - и тем не менее неумолимый закон. В этом состоит величие великих в истории философии, что они следовали этому закону - каждый на свой лад и в своих границах. И крайне редко они при этом отдавали себе отчет в этом следовании закону, увлеченные вещами, которые они считали необходимым исполнить, и это исполнение было идентично их знающему проникновению. Род процедуры формировался у них в восприятии объекта, в оценке его способа данности, которое нельзя изменить, а можно только признать или ошибиться на его счет. Ни один философски выдающийся ум никогда не работал со схемой метода, которую он мог бы переносить без разбора от объекта к объекту. Схемы это всегда выдумки эпигонов. Пожалуй, можно сказать, что методологическое рассмотрение само по себе является делом эпигонов. Не совсем так. Здесь тоже самые важные подсказки всегда исходят из оригинального мышления лидеров и первопроходцев. Их первопроходство состоит именно в том, что они указывают на новые «пути» к проникновению. Но эта «мудрость» не рождается путем вычисления метода, или путем объективации метода и даже собственных действий, но в глубоком проникновении в суть дела, во вхождении в него. Методическое сознание, как и везде, так и здесь, - вторично. Сам метод растет в работе, в контр-игре пробной попытки, неудачи и удачного завершения. И его замечают как раз тогда, когда он срабатывает. Знание о нем следует за этим. Предварительный набросок метода до отправления в путь исторически никогда не существовал, а систематически представляет собой вещь невозможную. 
Это дает пощечину большинству современных методологий. Но здесь нужно переучиваться. Весь методологизм представляет собой зависание на вторичном, пропуск основополагающего, эпигонскую депрессию философии. Аналогично и всякое занятие диалектикой как методом является бесплодным, если оно не приводит к тем вещам, для которых он предназначен. Вот точка, в которой наше настоящее исследование должно преодолеть позицию методического рассмотрения. И на это указывает путь к существу гегелевской диалектики. Ибо в этом величие этой диалектики, что она - совсем не методология, что она от раза к разу показывает иной лик, что она обращается в своем тонком приспособлении к объекту. Она исполняет основной закон всякого философского познания - закон приспособления к подходам - в некотором смысле, как никакой другой метод, который можно сформулировать. И вместе с тем она перерастает свой характер только лишь метода; поэтому она более чем метод и методологически не характеризуема. Да, именно поэтому она ускользает от методического сознания даже в мышлении того, кто работает с ней. Не случайно свидетельства Гегеля о ней были настолько скудны, что он тоже не знал о ней больше, чем о схеме трех шагов, к которой она не сводится. Это может быть ее горестной судьбой - это противоречит основному принципу Гегеля, согласно которому все бытие «в себе» исполняется только в своем бытии «для себя»: то, что диалектика в мышлении и в своем строении мысли есть «в себе», именно в этом же мышлении не становится всякий раз «для себя». Если бы она становилась для себя, Гегель имел бы и должен был бы иметь адекватное знание о ее сущности. Он должен был быть своим собственным эпигоном. То, что он им не был, что в его мышлении оставалась преобладающей преданность вещам от начала до конца, что он таким образом не исполнял свой же основной принцип в своем мышлении - не его недостаток, а его преимущество. И именно здесь укоренена сила интеллектуального лидерства, которая по-прежнему исходит от него еще и сегодня во многих проблемных областях.

III

В какой-то момент Гегель, конечно, получил полное представление о тайне своей диалектики. И здесь он решительно противостоял всему, что было сказано о ней до и после него. Он видел в ней не процесс конструирования, не говоря уже о дедукции, а более высокий род «опыта». Это уникальное 
собственное свидетельство удивительной глубины в современной истории. Рейнгольд пытался в продолжение кантовской концепции «трансцендентальной дедукции» вывести все категории из единого основоположения. Фихте подхватил эту идею. Наукоучение 1794 года - попытка дать такое выведение в диалектической форме. Поэтому диалектика Фихте имеет очевидно дедуктивный характер. В контексте этого развития Гегель выступает - как минимум в «Логике» - как завершитель этого начинания Рейнгольда, и в свете этой взаимосвязи его диалектика также выглядит как разновидность вывода. Эта видимость продолжает преследовать его вплоть до нашего времени. Она коренным образом заслонила ее смысл и сущность и наградила Гегеля недопониманием, которое мстит развитию систематической мысли все последние сто лет.

Уже беспристрастный взгляд на реальный диалектический процесс мог бы поучительным образом свидетельствовать об этом. Его течение всегда ведет вверх от низших форм к высшим; оно показывает, как на каждом этапе внутренняя противоречивость разлагает то, что кажется единством, если оно не воссоединяется в более высоком и более целостном единстве. Поэтому, конечно, она указывает на высшее, но она не выводит его из низшего. Здесь вывод является просто невозможным: более богатые и более полные формы никогда не могут «следовать» из более бедных и более элементарных, и Гегель никогда не играл с идеей о том, что этот порядок вещей может быть отменен в диалектическом опосредовании. Если мы желаем здесь увидеть отношение зависимости, которое можно обнаружить в диалектике, то оно как раз обратное: низшее всегда зависит от высшего, и если диалектика начинается с высшей точки, чтобы показать в нисходящем тренде зависимое, тогда можно было бы говорить во всяком случае о «выведении». Но это не представляет собой ни мнение Гегеля, ни истинный ход диалектики. Скорее, это - определенная восходящая тенденция во всех областях - и проведенная через все работы Гегеля. Она всегда начинается с самого низкого уровня и возрастает последовательно до высшего. Таким образом, она совершает путь, направленный в противоположном направлении по отношению к тому, который проходит лежащее в основе зависимое. Или - если воспользоваться известным образом - она поднимается вверх звеньями цепи, которые все зависят друг от друга и все выводятся из самого высокого звена. Таким образом, она представляет на всем протяжении путь от вторичного к первичному: отношение cognoscendi, которое никоим образом не может быть приравнено к отношению ratio essendi, хотя оно пронизывает целое. 
Вот почему она не имеет никакого отношения к выведению. Она представляет собой восхождение. Или в другом образе: она входит извне внутрь. Она следует естественным путем всего человеческого знания, ведущим от данного и очевидного к скрытому и глубокому. Однако в тот момент, когда это становится очевидным, сказанное Гегелем о том, что диалектика представляет собой «опыт», показывает все в правильном свете. «Опыт» не следует понимать узко, как если бы он был связан с восприятием. Мы обретаем опыт разными способами - через людей и их деяния, с их собственными успехами и неудачами, их счастьем и страданиями, заслугами и провинностями. Каждый человек «переживает» свою судьбу, как личную, так и историческую, а также переживает всеобщность человеческой доли, «движение мира», внутренние и внешние пределы возможного. В этом смысле существует также внутренняя судьба познания, которое частично создается его объектом, отчасти его собственным своеобразием. В своем проникновении в объект познание испытывает не только объект, но и свои собственные кондиции. Продвижение в обоих отношения - последовательное исправление ошибок; и каждое такое исправление - это переучивание не только в отношении вещей, но и в отношении себя.

Если подняться до осознания следующего шаг за шагом изменения знания о себе самом и совершать это снова и снова на пороге нового проникновения в объект, то мы окажемся непосредственно перед тем, что Гегель называет диалектикой. В этом смысле он описал эту ситуацию во введении к «Феноменологии» в качестве «опыта», который сознание осуществляет с самим собой и со своим объектом. «Феноменология духа» - это путь, которым идет сознание, испытывая себя, становясь самосознанием. Это его собственный объект. Но оно не понимается непосредственно в его сердцевине и его сущности, а извне; то есть с точки зрения объекта. И этот путь опыта самого себя - это не нечто дополнительное, которое впервые должен был бы осуществить философ. Философ, напротив, только следует за ним. Он находит все стадии в развитии духа - как в индивидуальном, так и в историческом - ему нужно только войти в их ритм, исполнять его вместе с ними. Он входит в живую контр-игру встречи и промаха, единодушия и противостояния, в которых происходит это развитие, и в котором дух проходит через «ряд форм», которые он принимает. Такое «переживаемое» самосознанием движение - это как раз и есть диалектика. 
Поскольку обычно придерживаются укоренившихся предрассудков, искажающих образ гегелевской диалектики, это должно показаться парадоксальным.

Не следует забывать, что сам Гегель во многом способствовал недопониманию. То же предисловие к «Феноменологии» говорит о диалектике как о «процессе, который порождает свои моменты и проходит через них», причем движение пройденного приравнивается к «истине». Подобные выражения встречаются часто, и если их вырвать из контекста, в котором они находятся, то они, похоже, доказывают обратное. И поэтому обычно считают, что слово «опыт» в диалектическом мышлении не должно в конце концов восприниматься серьезно.

Но такое убеждение остается лишь внешним. Оно отрывает метод от вещей, на которые он нацелен, и не может больше их из него понять. Это ошибка всякого только лишь «методологического» убеждения. Основой всего этого отношения является скорее то, что этот «процесс» вместе с «порождением его моментов» и «протеканием» чего-либо в ходе становления сознания является чем-то реальным и данным в опыте. И в нем действительное духовное бытие фактически оказывается «пережито». Порождение моментов не падает жертвой философской мысли; их не нужно порождать, потому что мышление их скорее преднаходит. Оно проходит через них как через уже пройденные, а именно те, что пройдены на пути становления самого духа. Конечно, это возможно только в том случае, если диалектика - нечто большее, чем метод философской мысли, если это движение по пути становления самого духа. Только таким образом философское мышление может упорствовать в отношении опыта - собирать и сохранять именно то, что выявил путь становления. То, что это последующее движение также должно быть непрерывным, - это, конечно, должно быть само собой разумеющимся.

Это отбрасывает свет на характер движения диалектики, который хорошо приспособлен для просвечивания изнутри наружу. То, что выглядит как схематичность или спекулятивный произвол, скорее является закономерностью, которая твердо привязывает мысль к ее объекту. Эта мысль должна быть подвижной, она должна проходить через определенные фазы, этапы, даже целые траектории, потому что ее объект в том виде, в котором он «проявляет себя», проходит через них же. Закон движения в диалектическом мышлении не является субъективным, не является законом мысли. 
Он представляет собой закон опыта, который впервые переживается в продвижении самой мысли. И в этом отношении его, скорее, можно назвать законом бытия. В своем истинном основном модусе он не понимается. Он проявляется только в последующем исполнении мысли, в траектории ее движения, ее резонансного ритма. Здесь лежит причина сокрытия, нераскрытой тайны сущности диалектики. Она, как и все внутреннее, понимается только в проявлении вовне. И именно в этом она одновременно остается непонятной. Из этого вытекает недостаточность схематического определения, поверхностность ее формального закона, антитетика; из этого же вытекает иллюзорность «следований» и дедуктивности». Эти недостатки в их понятийной форме не могут быть «устранены». Ввиду такого положения мало что можно сделать, кроме как оставить всю эту часть ее проблем - методологическую - в стороне, что значит оставить ее как тайну виртуозности этого скрытого мастерства и обратиться к онтологической проблеме, которая проявляет ее явно.

\section{IV}

По этой причине здесь следует игнорировать всю логическую и понятийно-техническую сторону диалектической проблемы. Не потому, что будто бы она не важна или как будто она не имеет к ней никакого отношения. Напротив, здесь как раз открываются совершенно доступные пути исследования. Вопрос о расплавлении фиксированных понятий и их подвижности является старым, хотя и все еще мало разъясненным. И он заслуживает своей собственной серии исследований. Он представляет собой естественную проблему границы формальной логики и властно ведет к ее расширению. Но все это влечет в другом направлении и уводит от Гегеля. Логическая сторона как раз в наибольшей степени обрезана у Гегеля. Его мышление было и остается метафизическим, даже в «Науке логике». В этом направлении, напротив, возникает другой вопрос: реальная ценность диалектики.

Внутреннее отношение этого вопроса к формально-логическому ясно показывает зависимость последнего. Если диалектика расплавляет все понятия, делает их текучими и позволяет им превращаться друг в друга и, таким образом, противоречит традиционной логике, оправдание этого действия следует оценивать исключительно в зависимости от того, требует ли его объект или нет. Но это означает, что это зависит от того, является ли объект стабильным или «текучим». Если мир, с которым мы имеем дело, является прочной 
конструкцией, правят ли в нем идеи Платона или иные морфологические принципы вечного подобия, то всякая текучесть фиксированных понятий выставляется за дверь, и расплавление всякого истинного «понятия» является радикальным промахом. Но если сам мир растворяется в размытых переходах, его формы смешиваются друг с другом, то логика фиксированных понятий - это промахи и проскакивания мимо цели, а реальное понимание начинается с расплавления понятий. Как бы логически это последнее не выглядело, его значение для познания зависит не от логического, а от онтологического фундаментального вопроса.

Мы должны подойти к нему. Он идентичен вопросу о том, является ли диалектика чем-то большим, чем просто методом. Ибо, если объект познания более подвижен в своих определениях, то движение понятия, если оно хочет понять его, должно входить в его собственное движение, подражать ему в мышлении. Если с точки зрения мышления это означает не что иное, как движение понятий как отображение реального движения, то диалектическое мышление является аналогом реальной диалектики.

Хорошо известно, что диалектика Гегеля выступает именно с этим притязанием. Не о «понятиях» бытия, ничто и становления идет речь в начале его Логики, но о бытии, ничто и становлении самих по себе. Это не «понятия» конечности и бесконечной прогрессии, которые ограничиваются и антитетически противопоставляются, пока они не превращаются в «понятие» циклической бесконечности, но к сущности самой конечности принадлежит процесс как заранее предположенный, и непрерывное чередование обоих приводит к замкнутой бесконечности. И если бытие вообще сводится к основанию в начале «рефлексии», то эта рефлексия и регресс не трактуются как присущие мышлению или понятиям, а как в-себе-обращение всякого саморазвития самого Бытия как такового Понятия же только толкуют это самодвижение, воспроизводят его, являются его представлением в философском мышлении.

Подобно тому, как в этих примерах, обстоит дело со всей гегелевской логикой, феноменологией, философией права и историей, коротко говоря, со всей системой. Рассуждение, таким образом, приходит к тому, что вся развитая диалектика является реальной диалектикой, что шаг за шагом проявление противоречий, антитетичности и слияния в синтезе принадлежит самой вещи, что в ней все диалектическое движение является чем-то реальным, и поэтому движение мысли, которое следует за ним, имеет смысл просветления вещи. 
Притязания, выдвинутые им, конечно, очень метафизичны. Ход доказательства этой законности мы никоим образом не находим у Гегеля. Для него вопрос был предварительно решен и решен на основе его рационального идеализма. Ибо, если Абсолют, воплощенный в мире, есть разум, и если человеческий разум на его высших ступенях (то есть в философской мысли) является самосознанием этого мирового разума, то ему не может не быть присуще, что в его саморазвертывании и движении саморазвертывания он представляет саморазвертывание и движение мира. Этот вывод является самоочевидным, если упускается предпосылка. Гегель воспринял ее как очевидную, как само собой разумеющуюся. Таким образом, он отменил всякую дискуссию по этому поводу, - но, разумеется, и всякий вопрос о правомерности. Оспаривать устрашающий догматизм такой предпосылки было бы смешно. И если бы для него и в самом деле весь смысл диалектики был бы завязан на реальное движение, то это имело бы смысл, в деструктивном смысле.

Это то, что критики всегда говорили о Гегеле. Они провели над ним слишком короткий судебный процесс. Они игнорировали многократно проделанный опыт философского мышления, свидетельствующий о том, что истинные и прочные достижения великого ума никогда не стоят и не падают вместе с его системой, что любое прокладывающее новые пути понимание, как правило, превращается в спекулятивную конструкцию, но все еще остается воззрением, распознаваемым эпигонами под обломками рухнувшей системы. Работа по восстановлению должна быть начата после завершения критики, кстати, дешевой, поскольку коллективной. Что же произошло? Что представляет собой сегодняшнее исследование Гегеля, когда оно меряется этой непреложной задачей? В целом по-прежнему существует спор между гегельянцами и анти-гегельянцами, теми, кто рассматривает диалектику в догматическом смысле рационального идеализма как панацею, и тех, кто отвергает ее со всеми ее очевидными достижениями. И между крайностями, как и прежде, отсутствует трезвая, критическая работа оценки.

В этом смысле поставленный вопрос снова актуален. Его нужно ухватить в самом его корне. И это значит - он не может быть решен в общем обзоре, но только при точном изучении отдельных диалектических траекторий. Только в таком детализированном исследовании становится ясно, где диалектика реальна, а где нет. Общая оценка будет сделана только на основе такого анализа. В исполнении этой задачи мы все еще находимся в самом начале. Результат нельзя предпослать движению. Его можно указать только 
со ссылкой на примеры движения к нему. Это должно выглядеть следующим образом.

Прежде всего, должна быть предпринята ориентация в проблемной ситуации. Амбициозное притязание Гегеля обосновать рациональный идеализм хотя и выглядит метафизично и мобилизующе, но оно не утопично. Проблема реальной ценности логической формы мысли ни в коем случае не затрагивает диалектику. Это касается таким же образом формальной логики со всеми ее законами. Если понимать под последней не только три основных закона, среди которых закон противоречия занимает в некотором роде центральное положение, но все законы суждения и вывода, то вся оценка значимости вывода будет зависеть от одного вопроса: имеют ли эти законы онтический смысл? Если, например, суждение de omni et nullo выражает отношение, которое не относится к числу порядков реального, все наши дедуктивные выводы иллюзорны и не могут сообщать знания. Внутренняя логическая связность как таковая действительно полностью независима от истины или ложности выводов. Это просто означает, что conclusio должен иметь значение, «если» имеют смысл предпосылки: вопрос об этом нисколько не является логическим вопросом и больше не подпадает под какие-либо логические законы. Внутренняя корректность вывода, так сказать, находится полностью по ту сторону истинного и ложного. Но в некотором ином смысле это затрагивает проблему истины. И этот смысл проявляется везде, где вывод представляется как посредник нового знания - практически везде, куда он включен.

Это хорошо известная и часто высказываемая связь: только в мире, в котором общие формы или законы определяют индивидуальный случай, логические выводы нашей логики мышления могут иметь когнитивную ценность. В мире, который не подлежит какой-либо типологии, они не имеют значения, и то, что они приписывают ценность истине, является обычным обманом. Реальное значение логики зависит от соответствия законов мышления и бытия. Это согласование всегда считалось само собой разумеющимся в более старой «классической» логике. Уже Аристотель рассматривал отношения понятий непосредственно как отношения бытия, и на этой основе его учение о форме формируется в Книге Z Метафизики. В схоластике эта точка зрения остается преобладающей; она заложила основы средневековой онтологии, пока не была окончательно искоренена из-за вторжения номинализма.

Однако даже в общей логике понятие формальных законов как законов бытия является полностью метафизическим тезисом, который никоим 
образом не может быть доказан. С течением времени высказываться в защиту этой точки зрения стали намного более осторожно. Разумеется, отступление логики к требованию чисто имманентной корректности заходит слишком далеко; оно полностью устраняет проблему познания и ценности истины логических операций - проблему, которая должна быть центральной и актуальной в логике. Эта проблема просто должна быть разрешена. В наши дни это решение еще не принято, и, возможно, философия никогда ее не решит. Но, безусловно, допустимо придерживаться приведенного выше суждения как своего рода ориентира, что только в рамках соответствия логического и онтического законов логическое заключение может передавать истину.

Эта ситуация чрезвычайно поучительна. Это доказывает, что в формальной логике мы находимся в той же апории, что и в диалектике. Здесь и там это касается реальной оценки мыслительных операций и контекстов мысли, здесь и там основная проблема, стоящая за проблемой формы, является онтологической; и здесь и там это показывает тот же характерный метафизический эффект, который проявляется в том, что мы не можем дать окончательного ответа. Проблема выходит за рамки познавательной компетенции - через радикализм, у которого все здесь и там основано на одном базовом принципе. Независимо от того, действителен ли этот принцип, его нельзя решить априорно. И опыт со своей стороны не может гарантировать общее решение, несмотря на некоторое подтверждение в эту сторону.

Единственное отличие состоит в том, что в формальной логике проблема имела долгую историю и стала достаточно ясной, но диалектика все еще находится в неведении. Но по этой причине, возможно, настало время заняться ею.

Само собой понятно из сказанного, что не может быть обобщенного решения вопроса о диалектике. Он не подлежит систематическому изучению, как должна оцениваться реальная ценность диалектических отношений понятий; скорее, вопрос лишь в том, насколько диалектика Гегеля, как она существует в его работах, претендует на то, чтобы считаться реальной диалектикой.

Прежде чем обсуждать примеры, нужно сказать, что это требование сильно отличается в зависимости от конкретных объектов и близости к явлению, которое составляет отправную точку. В этом пункте наблюдается 
большая разница в предметных областях внутри самой гегелевской диалектики. И легко предвидеть, что самая большая близость к этому феномену должна обнаружиться тем, где мышление Гегеля близко к реальному, описывая его посылки. А это, как известно, имеет место повсюду в интеллектуальных сферах, в философии права и истории, в эстетике и в феноменологии духа. Эти работы и лекционные циклы всегда считались наиболее читаемыми; благодаря изобилию и пластичности их материала они также рисуют то, что задумано, еще рельефнее. Да, в некоторых разделах у него есть нечто вымученное, что заставляет читателя в своем мышлении воспроизводить диалектические траектории, и, таким образом, мыслить самостоятельно диалектически. В «Логике» дело обстоит иначе. Трудность ее чтения хорошо известна. Но это ни в коем случае не основано на формальной несогласованности, даже на диалектической тонкости. Причина кроется в высоте абстракции, в масштабе воззрений, в невозможности связать заключение с понятным положением дел и наполнить содержанием; то есть она кроется в отстоянии от феноменов. Именно это дает этой работе уникальную высоту мышления: «Логика» - самая метафизическая и смелая работа Гегеля, и, возможно, одна из самых смелых философских книг. На удалении от конкретно данного диалектика освобождается от обратных связей, теряет почву под ногами, как бы парит в пустоте. И поэтому она рискует превратиться в противоположность тому, чем она должна быть, стать универсальным «опытом» конструирования. То, что мысль Гегеля поддалась этой опасности, является слишком известным фактом, чтобы о нем упоминать. С другой стороны, важно найти границу между «реельной» и «нереельной» диалектикой в своем собственном мышлении, то есть между тем, что справедливо претендует на роль настоящей диалектики, и тем, чему в этом должно быть отказано. Причем с самого начала должно быть ясно, что это также задает масштаб того, что является постоянным и преходящим в гегелевской философии, указанием к отделению в его духовном наследии вневременного от просто исторического и второстепенного.

Это требование само по себе сильно заряжено; нельзя надеяться удовлетворить его легко. И, конечно, можно лишь содействовать решению этой проблемы, а не решить. В конце концов, следует отметить, что сам вопрос представляет собой совершенно уместный, а не неправомерный подход к мышлению Гегеля. Он касается природы вещи, о которой говорит сам Гегель. Ибо это применимо во всей его диалектике: она утверждает, что является диалектикой бытия. Это предполагает, что сама вещь «изменяется», падает, вбирая 
противоположность от себя, поэтому нужно показать, верно ли это, и если это так, одинаково ли так везде.

Но в чем, следует спросить, должен состоять некий критерий ценности действительности? Как правило, предлагают две возможности: либо он должен проявлять себя в логической структуре самой диалектики, то есть в движении понятий, или должен быть показан в объекте, например, при сравнении с ним, если он дан иным образом. Здесь легко распознается общая апория критерия истины, поскольку она подходит всему человеческому знанию. Уже античные скептики показали, как критерий истины либо лежит в сознании и сам по себе должен стать представлением (содержанием сознания), либо лежит вне сознания в сфере объектов, и поэтому должен быть трансцендентным представлению. Скорее, в обоих случаях он не может быть критерием, поскольку в первом случае он субъективен и требует объективной действительности другого критерия; во втором случае, однако, он объективен, только недоступен для сознания, поэтому он не может служить этой цели.

Оба случая возвращаются в диалектику без изменений. В их понятийной структуре мы не можем ожидать найти какой-либо критерий. В лучшем случае это может только показать внутреннее несогласие. Это последнее не имеет большого значения в диалектической линии мысли. Очевидное противоречие вполне может соответствовать реальному отталкиванию в материи и, таким образом, быть «реальным», поскольку вся гегелевская диалектика движется в повторяющейся разработке противоречий. То, что являлось бы признаком неистинности в статично-дедуктивной логике и для каждой легитимной претензии на ценность вполне последовательно преодолевалось бы в диалектике, не может именно поэтому рассматриваться как признак объективной несогласованности. Если придерживаться этого и просвечивать гегелевскую диалектику на предмет несогласованностей, то мы не найдем абсолютно ничего. Она работает плавно и логично повсюду, следует своему собственному формальному закону, не дает никакого повода для возражения. Особенно это касается тех ее разделов, где она дистанцируется от явлений, воззрений и коллективного опыта. Она также безупречна и безукоризненна, когда поднимается в сферу высокой спекуляции и конструирования и дает критикам вескую причину покачать головой.

Никак не иначе и со вторым случаем. Если в объекте при сравнении диалектического суждения с ними, согласование расхождений должно быть 
возможно для демонстрации, то это означает ничто иное, как ожидать невозможного. Возможно, диалектический объект также может быть дан недиалектически - как и различные явления интеллектуальной, социальной и правовой жизни, - но тогда, во всяком случае, его реальная диалектическая структура не дается вместе с этим; и именно поэтому речь идет о том, обладают ли суждения ею или нет. Поэтому невозможность внешнего критерия является еще большей проблемой, чем общая проблема истины.

Мы должны взглянуть еще на нечто иное, на нечто третье - помимо формальной структуры и обращения к объекту. Для этого все еще есть возможность. Она лежит в начальной точке завершения диалектического движения мысли.

Из общего закона познания можно предположить, что каждый ход мысли, каждое рассмотрение чего-либо предполагаемого, является отправной точкой. Сама по себе последовательность мышления определяется в основном тем, что содержится в этой отправной точке, потому что она задает проблемную ситуацию, которая требует всех дальнейших действий. Однако сама она может иметь различную реальную ценность. Она может быть предрассудком, недоразумением, заблуждением, даже конструктивно-умозрительным предположением; но она также может быть действительно данным неустранимым реальным феноменом, может быть чем-то пережитым и актуальным, что в его оснащении еще не усмотрено. Если существует определенная, законосообразная форма, в которой происходит движение мысли, очевидно, что в этом случае, как и в другом, она должна, с равной последовательностью, приводить к мыслительным результатам, которые стоят и падают вместе с отправной точкой, то есть их истинностное значение полностью зависит от того, является ли эта отправная точка истинной или нет.

Это соотношение хорошо известно из логического вывода. Если сам вывод не содержит ошибок, то предложение имеет место: как предпосылки, так и вывод. Если они верны, то и последние тоже должны быть истиной. Предположим, что для диалектического движения мысли может быть использован тот же критерий реальности, как для логического вывода, из этого следует: реален как исходный пункт, так и сама диалектика, которая развита из него. Если исходный пункт реален, если он основан на феномене, данном и как-то «пережитом», то у нас есть основание, чтобы сделать диалектический «уклон» (Duktus) реельным и интерпретировать его траекторию как подвижную структуру объекта, но этот подход не основан ни на каком доказуемом 
факте. Если он сам уже является спекулятивным продуктом мысли, то диалектический уклон также должен быть заподозрен в нереельности.

Кроме того, если различие такого рода можно показать в начале диалектических проходов Гегеля, то есть также первый критерий для их окончательного решения в их реальной диалектической ценности или даже радикального разделения их на реельные и нереельные. Последствия этой перспективы могут быть очевидны с первого взгляда: здесь будут даны средства, чтобы отличить всего лишь исторические, преходящие, мертвые элементы в гегелевской философии от жизнеспособных и подчеркнуть чистый вклад разрабатываемого воззрения. Ввиду огромного проблемного материала, оставленного Гегелем, эффект от этих начинаний настолько велик, что никакие усилия даже самые трудоемкие - не кажутся слишком большими.

Само исследование, которое здесь является предметом, требует работы в течение целой жизни человека. Оно может быть объяснено здесь только эскизно. Вероятно, оно также должно быть признано нерешаемой задачей на протяжении долгого времени. Автор провел с ней два десятилетия и может хотя бы взглянуть на некоторые первые результаты сегодня. Результаты могут быть приблизительно обрисованы, но обоснования пока нет. Его можно получить только при самом детальном разборе подробностей. Таким образом, нижеследующее ограничивается основопологающим, используемые при этом примеры должны быть поняты скорее в качестве иллюстративных, чем ориентирующих.

Коротко говоря, гегелевская «Логика» в таком исследовании имеет самые серьезные предпосылки демонстрации ее как нереельной диалектики. Само исследование, которое здесь является предметом, стать делом всей жизни для человека. Оно может быть объяснено здесь. Вероятно, оно также должно быть признано нерешаемой задачей в течение долгого времени. Отсюда жизненное воздействие, которое исходит от этой части гегелевской системы философии права, историографии, философии религии и искусства. С другой стороны, враждебность естественных наук к этой самой системе; следовательно, наконец, общее отпадение даже эпистемологии от ее логики и вообе метафизической установки конца XIX века. 
То, что отражено в этом историческом развитии, не является совпадением. Оно в основном справедливо, хотя и его значение существенно больше, чем только быть объектом для критики. Это только критика, которая не знает причин этого развития. Такая критика работает только инстинктивно, поэтому у нее нет ограничений и нет почтения к достижениям. Это, по сути, не что иное, как «суд толпы», который, по мнению Гегеля, постоянно осуществлялся в мировой истории, но поскольку он слеп, он в то же время также несправедлив. Положительное может быть разработано только в строгом анализе и только с позитивной оценкой вклада вещи. В позитивном оценка зависит от нее, поэтому следует начинать с положительного, насколько отдельные примеры могут его продемонстрировать.

Что происходит с «опытом» в диалектике, наиболее ярко проявляется в известном диалектическом отношении «господина и раба», господского и служилого сознания из «Феноменологии Духа». Отношения, которые развивает здесь Гегель, представляют собой исходно-человеческое, исторически известное, и все же самое удивительное, что их можно рассмотреть в мышлении. Ибо они оказывается инстинктивно понятными в качестве неустойчивых отношений, которые несут зародыш несоответствия и в конечном итоге разрушают себя. Все это можно выразить очень не по-гегелевски, очень кратким образом: невозможно обладать властью и «господствовать» над людьми, но в то же время отказываться от власти управляемых и, следовательно, оказываться зависимыми от них, и наоборот: невозможно служить правящей власти, в то же время не обладать властью над правителями. Слуга получает ее просто потому, что правителю нужен он, его работа, его произведения и, наконец, он не может жить без него. Правитель позволяет слуге работать на себя; при этом он отказывается от прямого контроля в пользу посредничества вещей в удовлетворении жизненных потребностей, и он теряет свое господство. Если раб теперь поднимет это уроненное господство и использует его, уже он будет держать господина в своих руках. Он существует, при том что он есть только раб, и как раз поэтому он уже есть господин над господином; и господин существует, и поскольку он все еще господин, он уже является слугой слуги. Если слуга в один прекрасный день терпит неудачу в служении, господин сначала окажется этим задет, а потом, возможно, и пропадет, а раб, наоборот, не пострадает, он независим благодаря независимости своего труда и своих способностей. У него действительно есть власть. 
Гегель, разумеется, развивает это в более строгой диалектической форме. Но даже в этой сокращенной версии все еще ясно ощущается диалектический характер всех отношений. Также поучительно, насколько легко само отношение можно отделить от гегелевских понятий, не теряя его диалектического характера. Это не диалектика понятий, с которой мы имеем дело здесь, это диалектика вещей и диалектика видимости, которая под влиянием господства и рабства осуществляется на наших глазах, теперь мы можем либо понять ее как таковую, либо нет. Вещь сама по себе уже содержит в себе конфликт, и поскольку мы, как живые люди, являемся хозяевами или слугами в любой форме - мы «переживаем» этот конфликт нашей собственной жизни и судьбы, как и нашего реального господства и подневольного состояния. Таким образом, мы не «испытываем» его теоретически, не как наблюдатели или оценщики, а как те, на кого это отношение распространяет свою нестабильность и, снимая само себя, выполняет «диалектическое» движение, и поэтому здесь есть диалектика, которая является философской мыслью в фиксирующих ее понятиях как их движение, и то, как она логически их понимает, на самом деле уже содержится в опыте, причем в опыте, заданном проблемной ситуацией.

Другим примером, не менее известным, является диалектика наказания, разработанная в «Философии права». Конфликт в сущности наказания гораздо более спорный. Гегель предъявляет его следующим образом: как наказание может быть законным? Суть закона заключается в том, чтобы быть положенным свободно, но оно скорее имеет форму принуждения, можно наказать, следуя quia peccatum est или ne peccetur, но в обоих случаях невозможно понять, почему один человек имеет право наказать другого. Закон и общественный порядок не могут поддерживаться без наказания, поэтому именно этот конфликт необходимо решать. Он создает проблемную ситуацию, которая всегда дается и ощущается весьма живо в правовом сознании, и потому гегелевская диалектика наказания начинается с очевидного фундаментального феномена общественной жизни, предопределяющей ее очертания.

Если теперь рассматривать наказание как зло, совершенное по отношению к правонарушителю, то неясно, каким образом данное зло должно быть исправлено одномоментно. Разве что в том случае, если вы понимаете его как долг следовать закону. Это уже «второе принуждение», вызванное первым. «Первое принуждение» - это преступление, которое произошло. Для совершающего преступление принудителен правопорядок. Он снят в преступлении. 
Но поскольку сущность закона должна быть действительной и представлять реальный порядок вещей, реальное противоречие уже дается в преступлении, поскольку оно имеет место в рамках существующей реальной правовой системы, - вне его существует только несправедливость, право на произвольное индивидуальное деяние. Таким образом, преступление является принуждением к существующей форме и порядку свободы. Отсюда наказание представляется просто восстановлением свободы. Это действует настолько, насколько общественный порядок свободы в нем соответствует принуждению, которое произошло со вторым принуждением. Это может быть понято как реституция правовых отношений. Оно вполне отвечает этому понятию, и даже сам преступник возвращается в юридические отношения в случае его выхода на пенсию.

Эта диалектика, понимаемая как движение мышления, представляет собой не что иное, как изложение реальных отношений, существующих в жизни сообщества, а также ничуть не менее реального процесса, вытекающего из него. В этом смысле это диалектика, данная и испытанная в судебном процессе и пережитая в нем. Это реституция правовых отношений. Ввиду этого становится смехотворной попытка оправдывать наказание теорией задним числом - будь то предупреждение преступления или возмездие. Оно не нуждается в оправдании, потому что это живое движение существующего права. То, что такая несправедливость может существовать только в том случае, если она аннулирована, заключается в природе закона.

Два приведенных примера выбраны с учетом их актуальности в действительности общественной жизни - гегелевской, то есть в жизни «объективного духа». Насколько гегелевская диалектика наказания адекватно излагает юридическую теорию, живое юридическое сознание и отсылает к законодательству - про это хорошо известно, исторический отклик не заставил себя долго ждать. Гораздо менее известна диалектика «господства и рабства». Но актуальность и влияние здесь могут быть даже выше, если учесть, что теория классовой борьбы Маркса выросла из нее. Поскольку эта теория тесно связана с развитием социальных отношений вплоть до нашего времени, можно сказать, что диалектика, с марксистской точки зрения, очень существенно определила современную трансформацию экономической и политической жизни. Обоих мыслителей можно понять, только если серьезно относиться к характеру идеалистической диалектики. И это означает, что требование Гегеля выражать в логическом развитии самодвижение самой вещи в этом 
случае является оправданным. Односторонность господства и рабства представляют в себе самих неустойчивые отношения; они содержат в себе тенденцию растворяться и превращаться в другие отношения. Столь же неустойчивым в упорядочении правопорядка является нарушающее закон деяние; нарушая существующее целое, оно влечет за собой его внутреннюю регулирующую силу и подпадает под ее неизбежную власть.

С этой точки зрения легко видеть, что тоже самое относится ко всей гегелевской диалектике, которая в равной степени применима к опытно данному и реальному; и это означает, что в целом вся развитая диалектика в области интеллектуальной, правовой, политической, религиозной и исторической жизни заслуживает серьезного рассмотрения как реальная диалектика. Независимо от того, удавалось ли ее понимать везде одинаково, познавалась и оценивалась ли реальная структура духовного бытия везде правильным образом, - все это, конечно, другой вопрос. Здесь все равно должны быть даны самые разнообразные градации, которые необходимо будет подвергнуть подробному анализу. Но это не меняет базового понимания того, что вся эта диалектика представляет собой одну. Источники глубокого усмотрения сути подтверждают то, что недиалектическое мышление не может в нее войти. И эта ситуация становится тем более значимой, чем больше мы осознаем, что философия духовной сферы начинает разворачиваться в наше время в более крупном масштабе, и что у нас есть все основания рассматривать каждый фрагмент работы, которую мы проделали в этой области, как плодотворный.

\section{VII}

Именно эта положительная оценка предполагает, однако, что можно защитить себя от спекулятивных опасностей, присущих диалектическому мышлению, всеми инструментами критики. Следовательно, отрицательная радикальная сторона вышеприведенного утверждения не менее важна и нуждается в доказательстве. Это касается нереельности конструирующей диалектики, разработанной гегелевской логикой и представленной как метафизическая основа всех более конкретных соображений.

В качестве фундаментального примера можно взять диалектику «бытия и ничто», с которой Гегель начинает свою логику. Это выглядит так. Чистое бытие не может быть охарактеризовано иначе, чем в качестве чистого ничто, оно ничем не опосредуется, оно не отличается от ничто. То же самое касается 
ничто, движение мысли при этом следующее: оно начинается с обнаружения различия между бытием и ничто, но, хотя оно и предполагается, мышление не может найти его в них, бытие и ничто совпадают. Но переход от ничто к бытию образует становление, вхождение бытия в ничто, поэтому в становлении оба объединяются, становясь истинной их опосредования и действительно общей формой бытия.

Эти две вещи характеризуют стиль этой диалектики. Во-первых, это аргументация от движения мысли к вещи. В конце концов, это принятие «понятия» чистого бытия, которое нельзя отличить от «понятия» чистого ничто. То, что действительно «переходит» друг в друга, - это просто понятие. Точно так же, как бытие и небытие - если они должны быть «чистыми»сливаются друг с другом таким же образом, но это совершенно не очевидно из прохождения понятий. Однако теперь именно этот «переход» имеет место в мышлении в понятиях, которые сходятся на онтическом становлении, в котором бытие и ничто теперь не должно содержаться в виде моментов. Конечно, чисто мыслительный момент переносится в онтическое, но онтический переход не может быть найден.

И, во-вторых, где собственно находится исходная точка всей диалектики понятий? Где в мире есть чистое бытие и ничто? Где это происходит как явление? Нигде более, как в мышлении, в абстракции. И даже предполагаемое здесь понятие становления не соответствует данному в опыте становлению. Предполагается, что это старая до-элеатская концепция становления, которая знает рождение из ничего и уход в небытие. Уже предложение Парменида было направлено против него: ex nihilo nil fit. Никогда в более позднее время его не удавалось безнаказанно возобновить. Гегель, однако, не отказывает ему в признании, как если бы это положение никогда не приводило к абсурду. Становление, которое мы знаем на опыте, принципиально иное: так как никогда ничего не возникает из ничего, но всегда из чего-то иного и никогда не исчезает в ничто, а переходит в нечто иное, но столь же бытийствующее. Природа - великий поток этого перехода.

Таким образом, эта диалектика нереельна по двум причинам, без ущерба для их логически целостного течения. Она не имеет в качестве основания реального явления, она свободно парит в воздухе. Вот почему вы не можете справиться с этим изнутри. Она поэтому имманентна истине, но не трансцендентна. Это просто диалектика понятий. То же самое можно проиллюстрировать многочисленными примерами. Итак, возьмем для примера содержащую 
много удивительного диалектику конечного и бесконечного. Здесь, прежде всего, обманчива концепция долженствования, которую Гегель приписывает всем конечным вещам. Это движение в выхождении за пределы себя, в преодолении своих собственных ограничений, и исчезновение в чистом долженствовании. Эта концепция конечности не извлекается конечных вещей. Эти последние демонстрируют безупречный нейтралитет против своих ограничений. Она заимствуется из телеологического взгляда на мир, который предполагает «обнаружение» бесконечности за всяким конечным, и если допустить это предположение, то дальше она согласуется сама с собой, и понятийная диалектика так понятого конечного успешно ведет к бесконечному. Реальное значение не распространяется на нее.

В большем масштабе такой спектакль происходит с «дурной бесконечностью». Она оставляет конечное за своими границами, поэтому сама оказывается им ограниченной и поэтому оказывается конечной; с другой стороны, конечное всегда стремится за пределы себя и, следовательно, бесконечно в тенденции. В обоих предложениях мышление, очевидным образом, впадает в круг, и Гегель рассматривает этот круг как «истинную бесконечность», достигнутую мышлением. Более драматично, чем где бы то ни было, здесь можно увидеть, как движение понятий применяется для описания движения вещей. И здесь этот подход также терпит неудачу. И не существует данного в опыте феномена конечного, в который входило бы долженствование как таковое, и не существует бесконечного процесса, который бы в бесконечной череде ступеней становился конечным; наконец, фактическая бесконечность, лежащая в ее основе, циклична. А все эти метафизические предпосылки оказываются заимствованные из гораздо более высоких слоев бытия (духовного бытия), с которым они соотносятся в очень сомнительной аналогии. Та же картина со «становлением». Течение диалектики безупречно само в себе: как диалектика понятий, она не только совершенна, но и убедительна, доказательством чего является глубокое впечатление, которое она по-прежнему оказывает на некоторые логически чувствительные натуры. Но ей присуща внутренняя жесткость, она не держится за явление, это то же самое парение мысли в безвоздушном пространстве.

Диалектика сохраняет за собой репутацию игры ума с древних времен. Уже борьба платонизма против софистики была в значительной степени направлена против диалектической игры понятиями; продолжение этой борьбы в аристотелевской «Топике» хорошо известно, и все же некоторые из 
софистических заблуждений - вполне реальные, строго логически построенные парадоксы, которые неоднократно совершенно справедливо привлекали к себе внимание самых проницательных умов. Это как раз чисто формально-логическая проблема: возникновение противоречия в разработке концепции, и эта проблема заслуживает отдельного прослеживания. Это становится все более необходимым, поскольку диалектика понятий достигает наивысшей степени логической строгости и формального совершенства, особенно в вышеупомянутых случаях чисто концептуальных построений.

Конечно, гегелевские экскурсы в логику совсем не так формальны. В конце концов, некоторые из них можно поставить под сомнение. Но только это, то есть ее формальное совершенство, должно уже вызывать удивление. Кроме того, внутреннее противоречие, которое содержится в природе понятия, также встречается в ней повсюду, и всякий раз диалектика начинает разработки этого противоречия. В этом хотят видеть мастерство Гегеля. Но это сомнительное мастерство. Противоречие - это то, что по своей природе относится к сфере мышления и понятия. К противоречию относится «речение», и говоря логическим языком это означает суждение. Понятия и суждения могут, конечно, противоречить друг другу, потому что все утверждаемое в них находится в движении, но вещи, события, реальные отношения не могут, строго говоря, вступать в противоречие. На их уровне нет никакого суждения, высказывания и, следовательно, никакого противоречия. Но то, что в переносном смысле называется противоречивым в жизни и в действительности, на самом деле не противоречие, но противостояние. Столкновение сил, могущества воли, тенденций, даже гетерогенных законов существует во многих областях бытия, возможно, вообще во всех, но, конечно, во всех более высоких уровнях реального. Там конфликт является подлинным отторжением; он также может непосредственно иметь форму конфликта или открытой борьбы. Но он не имеет никакого сходства с противоречием, поскольку в противостоянии никогда нет отношения А к не-А, положительного к отрицательному; всегда встречаются две позитивности. Выражаясь логически, что отношения более контрарны, чем контрадикторны; контрарная оппозиция не удовлетворяется отношениями, поскольку она не выражает динамику реального отторжения.

Если взять это более точно - и совершенно формально точно, - то диалектика понятий, построенная на соотношении противоречий, никогда не может быть адекватным выражением реальной диалектики. Хотя мышление 
может иметь тенденцию обострять реальные отторжения в концептуальных формулировках до логических противоречий. Но это именно то, что фальсифицирует знание реальных отношений, и это способствует тому, что они промахиваются в основном мимо вещей в своем стремлении.

Перенося эту точку зрения на гегелевскую диалектику, мы видим, что она идеально подходит для дополнения ранее полученной картины. Ибо именно справедливость правосудия, с которой выступает в ней противоречие, осуществляет различие самыми разными способами. Безусловно, самая точная логика - это строгая разработка противоречия, она сознательно подчеркивает ее, работает с предельной логической точностью. И при этом утверждение о действительности этой диалектики теряет свою силу. Легкость, с которой сталкиваются противоречия, выдает свободно парящую диалектику понятий, держащую дистанцию от твердой почвы данного и опыта; и только спекулятивная высота абстракции, на уровне которой нелегко оперировать фактическим, скрывает опасность парения в безвоздушном пространстве.

Совершенно другое положение в феноменологии, философии права, философии истории и т. д.: достаточно часто кажется, что диалектика только здесь и излагается. Она делает это главным образом описательно, раскрывая неоднозначности всех видов, но редко поднимается на вершину понятийного понимания, и даже там, где понятия по форме приближаются к отношениям противоречия, тем не менее остается ясно видным предметное отношение, что безошибочно показывает характер взаимно признающей противоположности позитивного противостояния. Это очень легко увидеть в отношениях господства и рабства. В самом деле, господин неспособен быть «не господином», но он господин иным образом, чем «не господин». Точно так же слуга в другом смысле «не слуга». Оба находятся в сложной взаимосвязи. Очевидное противоречие - скорее положительный конфликт моментов в общих отношениях: власть, которой достигает слуга над господином, не та же самая, которую господин имеет над слугой, так что логически ни один из них не снимает друг друга, они не противоречат друг другу.

В общем, положение дел в гегелевской диалектике может быть сформулировано таким образом: чем резче это противоречие разработано в ней, тем совершеннее она работает в логическом смысле, и тем меньше может быть запрос на реализм. Чем больше противоречие отступает в ней, тем больше логический поток в ней уступает место описанию феноменов, и тем сильнее ее претензия на реальную диалектику. Противоречие в понятии не исключает 
конфликта в вещи; но и не гарантирует его. Конечно, вполне определенно можно сказать о противоречии и возникающем из него «движении» вещи только там, где конфликт проявляется как таковой, без какого-либо логического призрака. Но это возможно только там, где противоречие сводится и прорастает в диалектике понятий, так как там, где оно отступает, там проявляется структура вещи с ее внутренним реальным отторжением. 